\title{
L. Explanation of certain improvements in the construction and fastening of the frame timbers of ships or vessels, either when building, or when under repair, for the more effectually preventing the disunion of the parts caused by hogging, and the transverse bending of the hull
}

\section{Mr. John Walters}

To cite this article: Mr. John Walters (1815) L. Explanation of certain improvements in the construction and fastening of the frame timbers of ships or vessels, either when building, or when under repair, for the more effectually preventing the disunion of the parts caused by hogging, and the transverse bending of the hull , Philosophical Magazine Series 1, 45:204, 280-285, DOI: $10.1080 / 14786441508638433$

To link to this article: http://dx.doi.org/10.1080/14786441508638433

Published online: 27 Jul 2009.

Submit your article to this journal $\sqsubset$

山 Article views: 3 
concerns of Britain, in the Geological department of your very. useful work,

April 4, 1815 .

I remain, sir,

Your obedient servant,

A Cunstant Reader.

L. Explanation of certain Improvements in the Construction and Fastening of the Frame Timbers of Ships or Vessels, either when Building, or when under Repair, for the more effectually preventing the Disunion of the Parts caused ly Hogging, and the transverse Bending of the Hull. By Mr. JoHN WaLTERs, Architect, Fenchurch Buildings, London.

$\mathrm{B}$

B EFore I proceed to explain the proposed improvements, it is necessary to give an idea of the common method of ship-building, and of the prineipal improvements which the art has hitherto received.

The frame or skeleton of a ship, built according to the com. mon mode of construction, is coniposed of a number of curved timbers (called $r i b s$ ) placed at certain distances from each other, in planes, at right angles to the keel on which they all rest. In the intermediate spaces between the said ribs, are placed filling timbers, answering to the curve of the ribs, so that the void between timber and timber is from one to five inches. Athwart this frame are laid beams, at right angles to the keel, serving to hold together the sides of the ship and to support the decks, And for the purpose of strengthening the parts, a second range of curved timbers or inside ribs (called riders) are placed over the interior planking, but at a greater distance from each other than the ribs properly so called.

As in this construction all the timbers are disposed at right angles to the keel and keelson, and the planking both within and without is longitudinal, there is evidently no mechanical support to resist the action of gravity, from which radical defect all ships have a tendency to arch longitudinally and bend transversely by the sinking of the sides. The rementy of these evils is a great desideratum in naval architecture,

The constant strain which a ship experiences from an unequal distribution of weight, and the upward pressure of the water, is the cause of its becoming arched throughout its length, or (as it is called) hogged, to which cause may be added the partial pressure of the water in a longitudinal direction, which tends to compress the keel, and thereby to increase the curvature. The degree of curvature produced by these combined causes 
is of course different in different ships. Dr. Young has investigated this subject, the detail of which will be found in a very interesting paper pullished in the Philosophical Transactions, Part II. 1814. The result of his calculations applying to a 74 gun ship is as follows :

"Let $\mathrm{AB}$ represent the line of keel of a vessel which

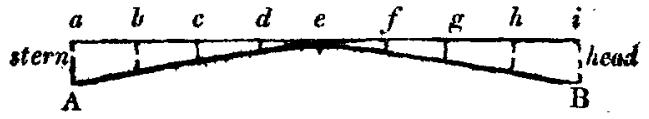
has hogged-imagine the line $a \dot{i}$ to be parallel to the horizon, touching the curve in $e$, and let it be divided into eight equal parts as in the figure. Then if we suppose the ship to be constructed of an uniformly flexible substance, the curvature will be such, that the fall of the keel below the imaginary line at each of the points $a, b, c, \& \mathrm{c}$. is proportional to the following numbers, viz. at $a, 17153$; at $b, 09421$; at $c, 03738$; at $d$, 00809 ; at $e, 00000$; at $f, 00854$; at $g, 03721$; at $h$, 08041 ; and at $i, 13525 . "$

The two eauses above mentioned, by which the arching of the ship is produced, act permanently; but when a ship is riding over the waves, she is occasionally borne up by the fluid in her central partonly, while the head and stern are forsaken. The strain hence produced, together with the agitation by which it is accompanied, far exceeds that arising from the mere inequality of the distribution of weight and pressure. Dr. Young estimates it, in certain cases, at nearly three times as mush; and notwithstanding the temporary action of this cause, he justly considers it as the most destructive, because, when the fastenings have been strained and loosened by the action of the waves, the ship will more readily give way to the operation of the permanent causes.

$\Lambda$ degree of curvature is also produced in a transverse direction, that is, at right angles to the foregoing, by the weight sustained by the sides being heavier than that in the middle, while the vertical pressure of the water is greatest in the neighbourhood of the keel. Thence arises an alteration in the transverse section of the ship, which assumes a form approximating to that of the annexed $f_{i}$ gure.

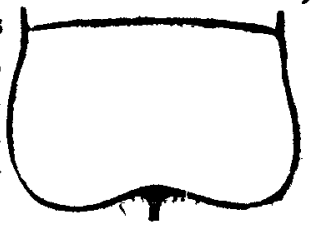

And lastly, there is also a tendency to a lateral eurvature. When a ship is "hove down" on her side, there is an obvious strain tending to produce this effect; and when a series of large waves strikes a ship obliquely, they must often act in a similar manner with immense force.

The principal improvement which has hitherto been made with 
with a view to counteract these evils inherent in every ship, and by which the lives of so many brave men have been lost, consists in employing oblique timbers. Mr. Seppings, who is the author of this improvement, fills the spaces between the frame timbers nearly to the height of the orlop or lower tier of beams, so as to make this part of the fabric solid; and omitting the inside plank, he places immediately over the frame timbers oblique riders, at an angle of about 45 degrees, (instead of placing them at right angles with the keel, as in the common construction,) and so disposed that the direction in the fore is contrary to that in the after part of the ship, and their distance asunder from six to seven feet or more; the upper ends abutting against the shelf-pieces (answering to the clamps of the common construction) which support the beans of the deck and the lower ends against the limber strakes. He next places two series of timbers longitudinally upon the joints of the frame timbers at the floor and first futtock heads, their ends dowelled to the sides of the riders. The framing thus formed by the oblique riders and longitudinal piecès represents two tier of compartments from the head of the floor timbers to the underside of the orlop deck, each compartment being of the figure of a rhomboid, in which is introduced a diagonal timber with an inclination opposite to that of the riders, thereby dividing it into two parts. Mr. Seppings also substitutes for the internal planking of the sides oblique braces placed in ships of war between the ports, the raking direction of these braces being lowest towards midships, and in the space on each side the centre port are placed two braces crossing each other. These comprise the principal improvements made by Mr. Seppings. Some others have also been introduced by him, but not necessary to be here noticed.

Dr. Young has published in the Philosophical Transactions his remarks upon this construction. He allows the use of oblique timbers to be good in principle. His arguments sufficiently prove their general utility, in tending to resist a change of figure in the ship; but he seems to doubt of the complete efficacy of the oblique riders and framing in the hold, when employed for the thick stuff of the ceiling. The filling in, however, appears to him wholly unexceptionable, and the braces between the ports to be decidedly more beneficial than the planks for which they are substituted.

Excepting Mr. Seppings's improvements, I know of none of any importance that have been introduced in to naval architecture for ages; but valuable as they are, there was room, left for further improvement, and a remedy for hogging still remained a desideratum. Having, as I conceive, contrived means for effectually obviating this defect in all ships, and having obtained His $\mathrm{Ma}$ jesty': 
jesty's Letters Patent for my invention, I am induced to submit the following explanation of it to the consideration of the publie, and of those who may be interested in such a subject.

The mechanical principle upon which this imptovement is founded is that of forming a complete and integral tross or support from the centre of gravity (whence the strength of the whole structure should as much as possible be derived), and so connecting the parts together, by embracing the entire fabric, that any tendency to a change of figure may be powerfully counteracted, and as much strength be given as the nature of materials will permit.

The frame or skeleton of a ship being constructed in the common way, a principal frame A (fig. 1 and $2, \mathrm{PI}$. VI), constructed of metal, or of wood and metal, is introduced in the space between the ribs, intersecting the vessel athwart the centre of gravity, connected across the ship by a tie-bar or beam B (fig. 2), and having the internal diagonal braces $\mathrm{C}, \mathrm{C}$. Also from the upper part of the said principal frame, the braces DD (fig. l), constructed of metal, are let in flush upon the outside and bolted to the frame timbers, and carried down in an inclined direction (being that of the shortest distance over the curved surface*) to the lower part of each extremity of the vessel, and connected each with its opposite one, in the concave parts of the bottom, by bolting through from one to the other, or by any other convenient method. Thus the whole frame of the ship is firmly connected together, and the weight of either end (supposing the ship supported under the centre of gravity) is counterbalanced by the other end, while the vertical strain, proceeding from the weight of the whole fabric, is transferred by the tension upon the braces $\mathrm{C}, \mathrm{C}$, to the principal frame $\mathrm{A}$. And also for the more perfect stiffening of the hull (when the spaces between the timbers are not filled in solid), and thereby obtaining a counter resistance to the weight of the middle (supposing the vessel supported at the ends); chocks or strutting pieces of timber scantling are tailed in between frame and frame behind or within the braces, which acting as arches when confined by the braces, discharge the weight of the vessel upon the butments at each extremity, which completes the truss. And it will appear evident, that so long as the truss remains perfect, not any weight or pressure can alter the relative position of any of the parts, whether the vessel is horizontal or inclined, unless caused by

* The utility of keeping the braces in the direction of the line of shortest distance is, that it presents the direct tension of the braces to every endeavour of the ship to change her figure, and prevents the possibility of the braces being moved by any force into a new position. 
some shock that would go near to effect the total destruction of the whole fabric.

The foregoing description being confined to the method of trussing smaller ships or vessels, the manner of extending this oystem (which with a little modification is applicable to ships of the greatest magnitude) is shown by figure 3 , in which $A$ is the principal frame; and B, B, the braces, as already described ; $C C$ are auxiliary braces; $D, D$, minor principal feames, one in the fore and the other in the after part of the body; $\mathrm{EE}$ are minor braces; and $F$ is an horizontal brace, connecting the heads of the minor braces, and forming a kind of longitudinal hoop to the upper part of the structure*. Chocks or strutting pieces are also tailed in at the back of these braces, similar to those before described, when the spaces are not filled in solid.

In ships of war the disposition of the principal braces ought to be so regulated as to be but little exposed to be shot away, and auxiliaries should be employed below low-water line, for additional security.

The braces before described are made of flat bars of metal in pieces of eonvenient length, so adjusted that the parts at which they are joined together, fall in the spaces between the ribs of the vessel, being connected by scarf joints wedged up for the purpose of equalizing the tension. The outer surface of the braces is kept flush with the frame timbers, and the bolt-holes in all of them are countersunk to receive the heads of the bolts, so that no part may present any obstruction to the planking.

In addition to the security afforded by this principle of trussing in constructing the ribs, I affix upon the sides over each butting joint of the timbers of which the rib is composed, a plate of iron or other metal extending above and below it, and bolted through the rib, by which means the ribs acquire great additional strength; an object of the first importance, even if only partially employed in assisting the weaker parts, and proteeting those most exposed to injury; as, in cases of a ship's grounding, it commonly happens that the floor timbers are forced in at one end, and the first futtocks broke off, while, by the tendency of the sides to sink, a transverse curvature is oceasioned by $a$ failure of the parts situated near the head of the floor timbers. In many other respects the employment of these iron elamps will be found of the most essential service.

Such is the general arrangement and application of my inven-

* As the tension upon the horizontal brace $\mathbf{F}$ is in the direction of the planking, this brace is not necessary to be used except in cases where great additional strength is required.

tion 
tion to practice. It is a system of framing, which resembles in some of its qualities, and in its effects and operations, the trussing employed in the construction of roofs, bridges, and other framed carpentry of great span, so that a vessel to which it is applied may not improperly be called a trissed ship or vessel; and this powerful support, superadded to the usual fastemings, must, it is presumed, infallibly produce the great objects proposed of preventing the depression of the two ends, and the butt ends and seams of the plank from opening, and also give general strength and security to the vessel.

The advantages resulting from this improvement are :

First, - That the durability of vessels will be increased, thus precluding the early and frequent repairs rendered necessary by the radical weakness of the present mode of construction.

Secondly,-That by means of the powerful support effected hy the truss the filling timbers between each rib may be omitted, thereby making a very considerable saving in the first cost, after allowing for the expense of the truss.

Thirdly,-The great benefits eventually to acerue to the mercantile world are, first, a reduction it the charges of freight, proportioned to the dimimution of the expense of building, the less frequency of repairs, and the comparative greater durability of the vessel; secondly, a more perfect security of the cargo from damage; and thirdly, a lower rate of insurance.

Bourthly,-The saving annually to their relatives, and to the community, a great number of valuable lives.

LI. On the Origin of the Pyramids of Egypt, and the Intention for which they were erected. By EDward Daniel. Clarke, LL.D.

[Continued from p. 200.]

A frer the numerous accounts which, during so many ages, have been written to illustrate the origin of the Pyramids, it is not probable that any new remarks will meet with much attention. Yet how few, among all the authors who have undertaken to investigate this subject; have ever ventured to express an opinion of their own! Struck by the magnitude of the objects themselves; by their immense antiquity; and by a consciousness of the obscurity in which their history has been veiled, every succeeding traveller contents himself with a detail of the observations of his predecessors, only showing the extent of the labyrinth wherein he is bewildered. Yet something perhaps might 